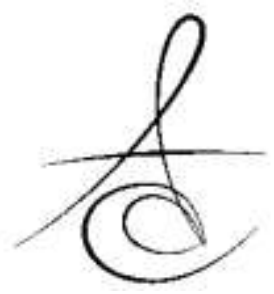

\section{SAĞLIK HİZMETLERİ MESLEK YÜKSEK OKULU ÖĞRENCİLERİNİN AĞIZ DİŞ SAĞLIĞI KONUSUNDA BİLGİLERİ}

\section{INFORMATION ON ORAL AND DENTAL HEALTH OF HEALTHCARE VOCATIONAL HIGH SCHOOL STUDENTS}

\author{
Doç Dr Gülser KILINÇ* \\ Öğr. Gör. Aysun MANİSALIGİL*
}

Makale Kodu/Article code: 3806

Makale Gönderilme tarihi: 26.07.2018

Kabul Tarihi: 19.09 .2018

DOI : $10.17567 /$ ataunidfd.461351
Gülser Kılınc: ORCID ID: 0000-0002-7422-0482

Ayşegül Yurt: ORCID ID: 0000-0001-6512-4950

Aysun Manisalıgil: ORCID ID: 0000-0001-7960-5317

Servet Kızıldağ: ORCID ID: 0000-0003-3565-279X

öz

Amaç: Ağız ve diş sağlığı (ADS) problemleri dünyada yaygın olarak görülen önemli bir halk sağlığı sorunudur. Bu çalışmada, Dokuz Eylül Üniversitesi (DEU) Sağlık Hizmetleri Meslek Yüksek Okulu (SHMYO) öğrencilerinin ağız ve diş sağlı̆ı konusunda bilgilerinin değerlendirilmesi amaçlanmıştır.

Materyal ve Metod: Kesitsel tipte bir araştırma olup, 10.03.2018-31.03.2018 tarihleri arasında DEU SHMYO öğrencileri arasında yapılmıştır. Katılan öğrencilere sosyo-demografik özellikler, ağız hijyen alışkanlıkları ve ağız diş sağlığı konusunda bilgi düzeylerinin sorgulandığı bir anket uygulandı. Veriler, anket formu yardımıyla gözlem altında toplandı. Tanımlayıcı veriler, yüzde dağılımları olarak verildi. Çözümlemede; parametrik test koşullarını sağlayan verilerde ortalamaların karşılaştırılmasında t testi, parametrik test koşullarını sağlayamayan verilerde ortalamaların karşılaşıııımasında Mann-Whitney U testi kullanıldı. İstatistiksel anlamılık için $\mathrm{p}<0.05$ değeri anlamlı kabul edildi.

Bulgular: Çalışmaya SHMYO'da birinci ve ikinci sınıfta okuyan 440 (\%69.1 kız, \%30.9 erkek) öğrenci katılmış ve öğrencilerin yas aralığı 17-30 (ort $19.64 \pm 8.24$ )'dır. Öğrencilerin \%47.2'ü düşük, \%45.3'si orta, \%7.5'i yüksek sosyoekonomik düzeye sahiptir. Öğrencilerin ADS konusunda bilgi düzeyi \%31.8 olarak saptanmıştı. Öğrencilerin ADS sorularına verilen doğru cevap oranı ile cinsiyet, yaş anne-baba eğitimi, gelir durumu, okuduğu program, sınıf arasında istatistiksel olarak fark saptanmazken, diş hekimine yılda iki kez diş muayenesine giden öğrencilerin bilgi düzeyinin istatistiksel olarak anlamlı olduğu saptanmıştır $(\mathrm{p}<0.017)$.

Sonuç: DEU SHMYO öğrencilerinin ADS konusunda bilgi düzeylerinin orta ve düşük düzeyde olduğu görülmüştür.

Anahtar Kelimeler: Ağız diş sağlığı, öğrenci, Sağlık Hizmetleri Meslek Yüksek Okulu

\title{
ABSTRACT
}

Aim: Oral and dental health(ODH) problems are a significant public health problem that is widespread in the world. In this study, it was aimed to evaluate the oral and dental health information of Dokuz Eylül University (DEU) Health Services Vocational School (SHMYO) students.

Material and Methods: It is a cross-sectional study among DEU SHMYO students between 10.03.2018-31.03.2018. A questionnaire was applied to the participating students to question their knowledge level about socio-demographic characteristics, oral hygiene habits, and oral health. The data were collected under observation with the help of a questionnaire. Descriptive data were given as percentage distributions. In the analysis; t-test was used in comparing the average data of parametric test results and The Mann-Whitney $\mathrm{U}$ test was used to compare the data that're not providing the parametric test conditions. A p-value of 0.05 was considered significant for statistical significance.

Results: 440 (69.1\% female, 30.9\% male) students studying at first and second grade in SHMYO participated in the study, and the age range of students was $17-30$ (mean 19.64 1.24 ). $47.2 \%$ of the students have a low level, $45.3 \%$ have a medium level and $7.5 \%$ have a high level of socioeconomic status. Students' level of knowledge about ODH was determined as $31.8 \%$. While the statistically significant difference was not found between the correct response rate of the students to the ODH questions and the gender, age, parental education, income status, the program they read, the level of knowledge of the students who went to the dental exam twice, was found statistically significant, $(p<0.017)$, respectively.

Conclusion: DEU SHMYO students' level of knowledge about ODH was moderate and low. Keywords: Oral dental health, students, Health Services Vocational School

* Dokuz Eylül Üniversitesi, Tıp Fakültesi, Çocuk Diș Kliniği, İzmir, Türkiye

Kaynakça Bilgisi: KIınç G, Yurt A, Manisalıgil A, Kızıldağ S. Sağlık Hizmetleri Meslek Yüksek Okulu Öğrencilerinin Ağız Diş Sağlı̆ı Konusunda Bilgileri. Atatürk Üniv Diş Hek Fak Derg 2020; 30: 48-54.

Citation Information: Kilinc $G$, Yurt A, Manisaligil A, Kizildag S. Information on Oral and Dental Health of Healthcare Vocational High School Students. J Dent Fac Atatürk Uni 2020; 30: 48-54. 


\section{GİRİŞ}

Sağlıklı bir toplum için bireyin kendi sağlığını korumaya yönelik çabalara önem vermesi ve sağlığını sürdürmeye yönelik bilgilerle donatılması oldukça önemlidir. ${ }^{1}$ Ağız diş sağlığı genel sağlığın önemli bir parçası ve yaşam kalitesinin belirleyicisidir. ${ }^{2}$ Aynı zamanda ADS çeşitli sistemik hastalıklarla da önemli ölçüde ilişkilidir. ${ }^{2-5}$ Ağız bakımının inmal edilmesi, sigara kullanımı, alkol, beslenme alışkanlıkları ve stres gibi çeşitli faktörler, ADS'yi olumsuz yönde etkilemektedir. Hayatın ilk yıllarında alınacak basit önlemler, bireyin tutumu ADS yönelik oluşabilecek sorunları önlenebilir. ${ }^{6}$ $\mathrm{Bu}$ tutumlar doğal olarak bireyin yaşam boyu edindiği deneyimler, kültürel algılar, ailevi inançlar ve diğer yaşam durumlarından etkilemektedir.,8 Birey her konuda olduğu gibi ADS konusunda ebeveynlerinden gördüklerini yansıtır ve onları rol model olarak alır. Bu model zaman içinde, eğitim öğretimin tüm kademelerinde ve tüm yaşamları boyunca verilecek bilgilerle bilinçli bir alışkanlık halini alır ve sonraki nesillere aktarılır. ${ }^{9}$ Burada bireyin yaşam tarzı, sosyoekonomik durumu aldığı eğitim ve çevresel faktörlerinin de oldukça etkili olduğu görülmektedir. ${ }^{10,11}$

ADS sorunları dünya üzerinde izlenen en yaygın halk sağlığı sorunudur. 2,8,12 Diş çürüğü özellikle yaşadığımız yüzyılın başlarından itibaren her yaş grubunu etkilemektedir. Ülkemizde de ADS önemli bir problemdir ve $12-13$ yaş grubu çocukların \% 80,0 inde diş çürüğü var olduğu belirtilmektedir. 20-24 yaşlarına gelindiğinde ise ortalama 5,5 adet çürük nedeniyle tedavi edilmesi gereken dişin var olduğu ifade etmiştir. 2,13 Periodontal hastalıkların görülme sıklığı ise 10 yaşında \%50 iken, ileri yaşlarda \%96'ya çıkmaktadır. ADS sorunları, çok yaygın olmasının yanı sıra hemen hemen tamamı önlenebilir. 2,14,15

Düzenli olarak diş hekimine gitme alışkanlığı olmayan toplumumuzun, ADS konusunda koruyucu yöntemleri diş kliniklerinden öğrenmeleri mümkün değildir. ${ }^{16}$ Ülkemizde genellikle ADS ile ilgili uygulamalar, diş hekiminin görev ve sorumlulukları arasında kabul görmektedir. Oysa bu sorun sağlık alanında çalışan tüm bireyleri ilgilendirmektedir. Sağlığın farklı kollarında çalışanların öncelikle kendi ADS konusunda doğru bilgilere sahip olmaları, sonrasında ise bu doğru bilgileri topluma aktarmaları gereklidir. ${ }^{2}$

Bu çalışmanın amacı, DEU SHMYO'da öğrenim gören öğrencilerin ADS konusunda tutum ve davranışlarını incelemek ve bu konudaki bilgilerini değerlendirmektir.

\section{MATERYAL VE METOD}

Kesitsel tipteki bu çalışmanın evrenini, 20172018 öğretim yılı içende DEU SHMYO öğrenim gören öğrenciler oluşturmuştur. Anestezi, ilk ve acil yardım, odyometri, radyoterapi, tıbbi görüntüleme teknikleri, tıbbi laboratuvar teknikleri, tıbbi dokümantasyon ve sekreterlik, nükleer tıp teknikleri programlarında okuyan 1 . ve 2 . sınıf öğrencileri araştırmaya dahil edilmiştir. Araştırmanın örneklemi ise, araştırmaya katılmayı kabul eden öğrenciler oluşturmaktadır. SHMYO bulunan toplam 700 öğrenciden bilgi düzeyi sıklığı bilinmeyen sıklık \%50, \%5 sapma ile \%95 güven aralığında en az alınması gereken örnek sayısı 248 olarak hesaplanmış, \%10 yedek alınarak en az 273 kişiye ulaşılması hedeflenmiştir.

Çalışma için araştırmacılar tarafından anket hazırlanmış, katılmayı kabul eden DEU SHMYO öğrencileri 10.03.2018-31.03.2018 tarihleri arasında formları doldurmuşlardır. Formların doldurulmasından önce öğrencilere araştırmanın amacı açıklanmış, katılımın gönüllülük esasına dayalı olduğu belirtilmiştir.

Anket sosyo-demografik (yaş, cinsiyet, anne baba eğitim durumu, gelir durumu) özelliklerin sorgulandığı yedi soru, bireyin ağız hijyen durumu (düzenli diş hekime gitme, diş fırçalama sıklığı, yaşanan ağız diş sağlığı problemleri, tütün ve tütün ürünleri kullanma durumu) sorgulandığı on iki soru ve ağız diş sağlığı bilgi düzeyini sorgulandığı on sekiz sorudan oluşmaktadır.

Araştırmanın değişkenleri: ADS bilgi düzeyi bağımlı değişkendir. ADS bilgi düzeyi, süt dişleri sürme zamanı, daimi dişlerin sürme zamanı, süt ve daimi dişlerin sayısı, diş fırçalama süresi, fırçalama sayısı, diş fırçalaması sırasında kullanılacak diş macunu miktarı, tütün ürünlerinin ağız diş sağlığına zararlı olup olmadığı gibi soruları ile sorgulanmıştır. Bilgi düzeyi puanı, her sorunun doğru yanıtına 1 puan verilerek hesaplanmış ve öğrencilerin anket sorularına verdikleri cevaplardan 10 ve üzerini doğru cevaplayanlar başarılı kabul edilmiştir.

Araştırmanın gerçekleştirilebilmesi için DEU girişimsel olmayan Klinik Araştırmaları Etik Kurulundan (01.03.2018 tarih ve protokol numarası 3841-GAO) ve araştırmanın uygulanabilmesi için ilgili kurumlardan yazılı izinler alınmıştır. Araştırma kapsamına alınan öğrencilerden yazılı onam alınmıştır. 


\section{İstatistik analiz}

Veriler bilgisayar ortamında 15.0 paket SPSS programı ile değerlendirilmiş, tanımlayıcı istatistiklerde sayı ve yüzde dağılımlar, ortalama ve standart sapma verilmiştir. İstatistiksel analizler ki-kare testi ile değerlendirilmiş, parametrik test koşullarını sağlayamayan verilerde ortalamaların karşılaştırılmasında Mann Whitney $U$ testi kullanılmış, $p<0.05$ değeri anlamlı kabul edilmiştir.

\section{BULGULAR}

Çalışmaya SHMYO birinci ve ikinci sınıfında okuyan 440'ı öğrenci katılmış ve anket formunu eksiksiz olarak doldurmuştur. Öğrencilerin 304'i (\%69.1) kız, 136'i (\%30.9) erkektir ve yaş aralığı 17-30 (ort $19.64 \pm$ 8.24) arasında değişmektedir. Annelerin \%4.6'i babaların \%9.7'si yükseköğrenim görmüştür. Öğrencilerin \%47,2'ü düşük, \%45,3'si orta, \%7,5'i yüksek sosyoekonomik düzeye sahiptir (Tablo 1).

Tablo 1. Sosyo-demografik özellikler ve dağıımı

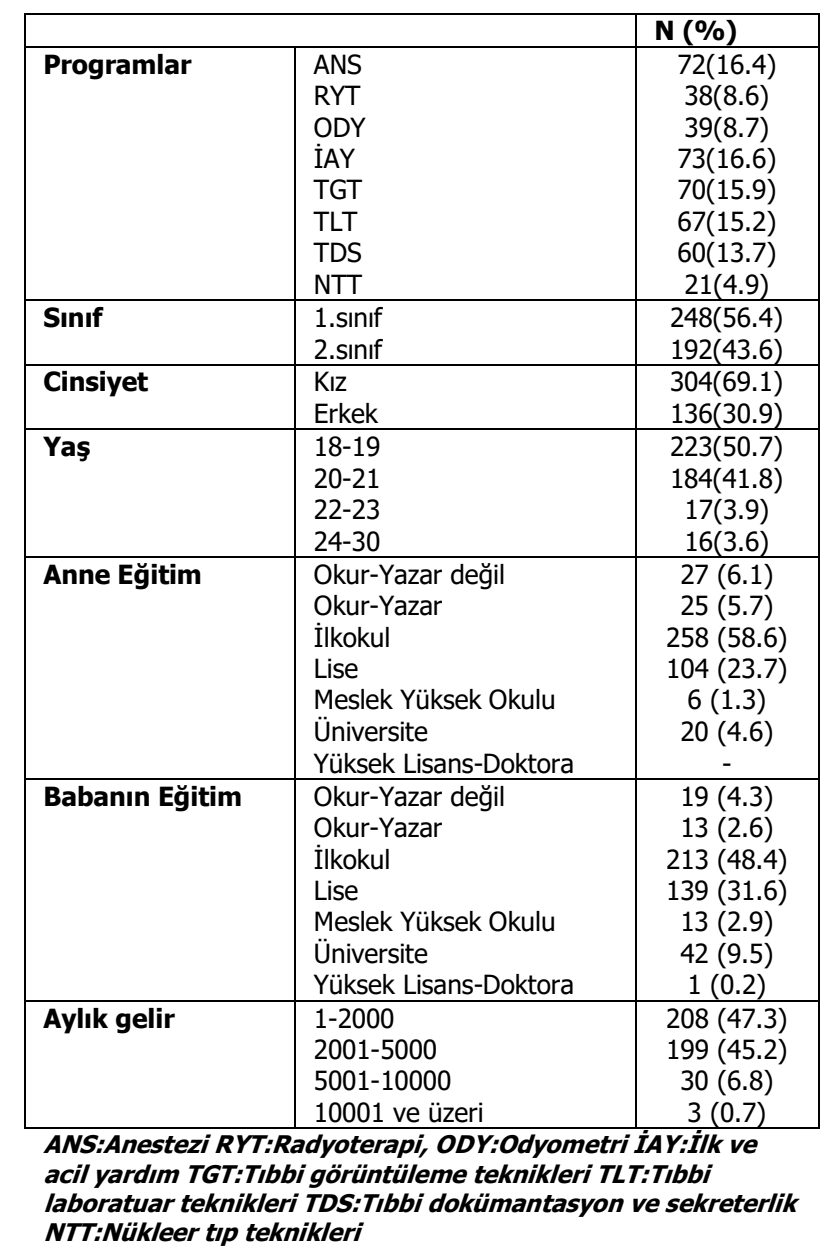

Öğrenciler diş hekime gitme sıklığı, diş fırçalama alışkanlığı, yaşanan diş ve diş eti sorunları, dolgulu ve eksik diş varlığına göre sınıflandırılmışlardır (Tablo 2). Çalışmamıza katılan tüm öğrenciler diş fırçasının olduğunu belirtmişlerdir. Öğrencilerin sadece \%18.8'si son 1 yıl içinde iki kez diş hekimine gitmiştir. Öğrencilerin \%62.2'nün günde en az iki kere fırçaladığını, $\% 25.5$ 'nün günde 1 kere fırçaladığını ve \%12.3'si dişlerini düzenli fırçalamadığını ve diş macunu alırken \%77.7'si diş macununun etkisine bakarak aldığını belirtmişlerdir. ADS problemi yaşayan öğrenci sayısı 342 (\%77.7) olarak saptanmıştır. Yaşanan ADS problemlerinde içinde en çok diş çürüğü (273 öğrenci), dişeti hassasiyeti (88 öğrenci) ve dişeti kanaması (88 öğrenci) varlığı tespit edilmiştir

Tablo 2. Katılımcıların ağız diş sağıı̆ını değerlendiren veriler

\begin{tabular}{|c|c|c|}
\hline & & N (\%) \\
\hline $\begin{array}{l}\text { Düzenli Diş hekimine gitme } \\
\left(Y_{I} / 2\right)\end{array}$ & $\begin{array}{l}\text { Evet } \\
\text { Hayır }\end{array}$ & $\begin{array}{r}87(19.8) \\
353(80.2) \\
\end{array}$ \\
\hline Diş fırçalama (gün) & $\begin{array}{l}1 \text { kez } \\
2 \text { kez } \\
\text { Düzensiz } \\
\text { Fırçalamıyorum }\end{array}$ & $\begin{array}{c}112(45.5) \\
274(42.2) \\
54(12.3) \\
-\end{array}$ \\
\hline $\begin{array}{lll}\text { Diş ve dişeti } & \text { problemi } \\
\text { yaşadınız mı? } & \\
\end{array}$ & $\begin{array}{l}\text { Evet } \\
\text { Hayır } \\
\end{array}$ & $\begin{array}{l}342(77.7) \\
98(22.3)\end{array}$ \\
\hline $\begin{array}{llr}\text { Yaşanan diş ve diş eti } & \text { ve } \\
\text { problemleri } & \text { (Birden fazla } \\
\text { cevap verilmiştir) } & \end{array}$ & $\begin{array}{l}\text { Diş çürüğü } \\
\text { Dişeti kanaması } \\
\text { Hassasiyet } \\
\text { Ağız Kokusu } \\
\text { Diş gıcırdatma } \\
20 \text { yaş diş problemi }\end{array}$ & $\begin{array}{c}273(79.8) \\
75(21.9) \\
88(25.7) \\
27(7.9) \\
16(4.7) \\
71(20.7)\end{array}$ \\
\hline Dolgulu dişiniz var mı? & $\begin{array}{l}\text { Evet } \\
\text { Hayır } \\
\text { Bilmiyorum }\end{array}$ & $\begin{array}{c}262(59.5) \\
176(40.0) \\
2(0.5)\end{array}$ \\
\hline Çekilmiş dişiniz var mı? & $\begin{array}{l}\text { Evet } \\
\text { Hayır } \\
\text { Bilmiyorum }\end{array}$ & $\begin{array}{c}113(25.7) \\
317(72.0) \\
10(2.3)\end{array}$ \\
\hline $\begin{array}{l}\text { Diş macunu alırken nelere } \\
\text { dikkat ediyorsunuz? }\end{array}$ & $\begin{array}{l}\text { Tadı } \\
\text { Kokusu } \\
\text { Fiyatı } \\
\text { Etkisi } \\
\text { Arkadaş tavsiyesi }\end{array}$ & $\begin{array}{c}30(6.8) \\
10(2.3) \\
52(11.8) \\
342(77.7) \\
6(1.4)\end{array}$ \\
\hline $\begin{array}{l}\text { Ağız diş sağlığı konusunda } \\
\text { bilgileri nereden aldınız? }\end{array}$ & $\begin{array}{l}\text { Anne-Baba } \\
\text { Öğretmen } \\
\text { Diş hekimi } \\
\text { Televizyon } \\
\text { İnternet } \\
\text { Diğer (Arkadaş, komşu) }\end{array}$ & $\begin{array}{c}173(39.3) \\
57(13.0) \\
130(29.5) \\
15(3.4) \\
30(6.8) \\
35(8.0)\end{array}$ \\
\hline $\begin{array}{l}\text { Ağız Diş sağlığı konusunda } \\
\text { ders almak ister misiniz? }\end{array}$ & $\begin{array}{l}\text { Evet } \\
\text { Hayır }\end{array}$ & $\begin{array}{l}297(67.5) \\
143(32.5)\end{array}$ \\
\hline Sigara kullanımı & $\begin{array}{l}\text { Evet } \\
\text { Hayır }\end{array}$ & $\begin{array}{l}127(28.9) \\
303(71.1)\end{array}$ \\
\hline $\begin{array}{l}\text { Başka bir tütün ürünü } \\
\text { kullanımı }\end{array}$ & $\begin{array}{l}\text { Evet } \\
\text { Hayır } \\
\end{array}$ & $\begin{array}{c}39(8.9) \\
401(91.1)\end{array}$ \\
\hline $\begin{array}{l}\text { Başka bir tütün } \text { ürünü } \\
\text { kullanımı (Hangisi) }\end{array}$ & $\begin{array}{l}\text { Nargile } \\
\text { Sarma tütün } \\
\text { Pipo } \\
\text { Puro }\end{array}$ & $\begin{array}{l}33(7.5) \\
4(0.9) \\
1(0.2) \\
1(0.2)\end{array}$ \\
\hline
\end{tabular}

Öğrenciler ADS konusunda bilgilerini \%39.3'ü ebeveynlerinden, \%29.5'u diş hekiminden aldığını belirtmişlerdir. Tümü bugüne kadarki eğitimleri süresince ADS konusunda bir eğitim almadıklarını ve \%67.5'i 
ADS konusunda bilgi almak istediklerini söylemişlerdir. Öğrencilerin \%28.9'u sigara, \%8.9'u ise başka bir tütün ürünü (nargile ve sarma tütün, puro) kullandığı saptanmıştır.

Öğrencilerin ADS bilgi düzeyini ölçmek için on sekiz sorudan oluşan soru formunda ortalama 8.24 \pm 2.44 (minimum;3, maksimum;14) soru doğru yanıtlanmıştır. Öğrencilerin \%31.8'i on ve üzeri soruya doğru cevap vermişlerdir. Bilgi düzeyi sorularına verilen yanıtlara bakıldığında; tütün ve tütün ürünleri diş ve dişetine zarar verir mi sorusu en yüksek oranda (\%92.0) doğru yanıtlanan soru olmuş, bunu diş macunu diş fırçasına ne kadar konulur (\%84.1), diş temizliğinde kullanılan ürünler nelerdir (\%78.0) ve dişin çürümesine neler neden olur (\%75.2) sorusu izlemiştir. Grubun yanlış yanıt verdiği sorular içerisinde ilk sırada; diş taşı oluşumunun nedeni nedir (\%5.9), kaza ile yerinden çıkan daimi diş yerine konulur mu (\%11.8), çocuklar dişlerini ne zaman fırçalamaya başlar (\%19.1) ve kaç adet süt dişimiz vardır (\%20.2), soruları olmuştur (Tablo 3 ).

Tablo 3. Uygulanan anketin çoktan seçmeli sorularına verilen yanıtlar ve yüzdelik dağılımları.

\begin{tabular}{|c|c|c|c|}
\hline Anket soruları & Doğru cevaplar & $\begin{array}{l}\text { Doğru cevap } \\
\text { verenler } \\
N(\%)\end{array}$ & $\begin{array}{c}\text { Yanlış cevap } \\
\text { verenler } \\
\mathbf{N}(\%)\end{array}$ \\
\hline $\begin{array}{l}\text { Tütün ve tütün ürünleri diş } \\
\text { ve dişetine zarar verir mi? }\end{array}$ & Evet & $405(92.0)$ & $35(8.0)$ \\
\hline $\begin{array}{c}\text { Diş macunu diş fırçasına } \\
\text { ne kadar konulur? }\end{array}$ & $\begin{array}{c}\text { Nohut } \\
\text { büyüklüğünde }\end{array}$ & $370(84.1)$ & $70(15.9)$ \\
\hline $\begin{array}{c}\text { Diş temizliğinde kullanılan } \\
\text { ürünler nelerdir? }\end{array}$ & $\begin{array}{c}\text { Diş fırçası, diş } \\
\text { macunu, diş ipi, } \\
\text { ağız gargarası }\end{array}$ & $343(78.0)$ & $97(22.0)$ \\
\hline $\begin{array}{l}\text { Dişin çürümesine neler } \\
\text { neden olur? }\end{array}$ & \begin{tabular}{|c|} 
Dental plak- \\
Mikroorganizmalar
\end{tabular} & $331(75.2)$ & $109(24.8$ \\
\hline $\begin{array}{l}\text { Kaç adet daimi dişimiz } \\
\text { vardır? }\end{array}$ & 32 adet & $301(68.4)$ & $139(31.6)$ \\
\hline Dişler kaç dakika fırçalanır? & 2-2.5 dakika & $251(57.5)$ & $187(45.5)$ \\
\hline $\begin{array}{c}\text { Diş fırçası kaç ayda } \\
\text { değiştirilir? }\end{array}$ & 3 ay & $50(50.0)$ & $220(50.0)$ \\
\hline $\begin{array}{l}\text { Dişeti hastalığının temel } \\
\text { nedeni nedir? }\end{array}$ & $\begin{array}{l}\text { Mikrobial dental } \\
\text { plak }\end{array}$ & 201(45.7) & $239(54,3)$ \\
\hline $\begin{array}{c}\text { İlk süt dişi kaç aylıkken } \\
\text { çıkar? }\end{array}$ & 6 aylık & $187(42.5)$ & $253(57.5)$ \\
\hline $\begin{array}{c}\text { Günde kaç kez dişler } \\
\text { fırçalanır? }\end{array}$ & İki kez & $176(40.0)$ & $264(60.0)$ \\
\hline $\begin{array}{c}\text { İlk daimi dişi kaç yaşında } \\
\text { çıar? }\end{array}$ & 6 yaş & $150(34.1)$ & $290(65.9)$ \\
\hline $\begin{array}{c}\text { Diş ipi günde kaç kez } \\
\text { kullanılır? }\end{array}$ & Bir kez & $126(28.6)$ & $314(71.4)$ \\
\hline $\begin{array}{c}\text { Flor diş çürüğünü engeller } \\
\text { mi? }\end{array}$ & Evet & $90(20.5)$ & $350(79.5)$ \\
\hline $\begin{array}{c}\text { Kaç adet süt dişimiz } \\
\text { vardır? }\end{array}$ & 20 adet & $89(20.2)$ & $351(79.8)$ \\
\hline $\begin{array}{c}\text { Diş çürüğü yapan } \\
\text { mikroorganizmalar } \\
\text { anneden bebeğe geçer mi? }\end{array}$ & Evet & $85(19.3)$ & $355(80.7)$ \\
\hline \begin{tabular}{|c|} 
Çocuklar dişlerini ne \\
zaman fırçalamaya başlar?
\end{tabular} & $\begin{array}{c}\text { İlk süt dişi sürer } \\
\text { sürmez }\end{array}$ & $84(19.1)$ & $356(80.9)$ \\
\hline $\begin{array}{c}\text { Kaza ile yerinden çıkan daimi } \\
\text { diş yerine konulur mu? }\end{array}$ & Evet & $52(11.8)$ & $388(88.2)$ \\
\hline \begin{tabular}{c|}
$\begin{array}{c}\text { Diş taşı oluşumunun } \\
\text { nedeni nedir? }\end{array}$ \\
\end{tabular} & $\begin{array}{c}\text { Mikrobial dental } \\
\text { plak }\end{array}$ & $26(5,9)$ & $414(94.1)$ \\
\hline $\begin{array}{l}10 \text { ve üzeri soruya } \\
\text { doğru cevap verenler }\end{array}$ & & 140(31.8) & $300(68.2)$ \\
\hline
\end{tabular}

Öğrencilerin ADS sorularına verilen doğru cevap oranı ile cinsiyet $(p=0.165)$, yaş $(p=0.077)$ anne-baba eğitimi $(p=0.091, p=0.689)$, gelir durumu $(p=0.586)$, okuduğu program $(p=0.176)$, sınıf $(p=0.985)$ arasında istatistiksel olarak fark saptanmazken, diş hekimine yılda iki kez diş muayenesine giden öğrencilerin bilgi düzeyinin $(p=0.017)$ istatistiksel olarak anlamlı olduğu saptanmıştır(Tablo 4). ADS konusunda öğrenciler tarafından en fazla 14 soru doğru olarak cevaplanmıştır. 1-5 arası soruya doğru cevap veren \%13.4, 6-9 arası soruya doğru cevap veren \%54.8, 10-13 arası soruya doğru cevap \%30.5, 14-18 arası soruya doğru cevap \%1.3 öğrenci olmuştur.

Tablo 4. Ağız diş sağlığı konusunda bilgi düzeyi sorularına verilen yanıtlar ve yüzdelik dağılımları.

\begin{tabular}{|c|c|c|c|c|}
\hline \multicolumn{2}{|c|}{$\begin{array}{c}\text { Ağız Diş sağlığı konusunda bilgi } \\
\text { düzeyi } \\
\text { (10 ve üzeri soruyu doğru } \\
\text { cevaplayanlar) }\end{array}$} & \multirow{2}{*}{$\begin{array}{c}\begin{array}{c}\text { Yanlış } \\
\text { Yanıtlay } \\
\text { an }\end{array} \\
44(61.1) \\
49(67.1) \\
13(61.9) \\
26(66.7) \\
27(71.1) \\
48(80.0) \\
42(60.0) \\
51(76.1)\end{array}$} & \multirow{2}{*}{$\begin{array}{c}\begin{array}{c}\text { Doğru } \\
\text { Yanitlayan }\end{array} \\
28(38.9) \\
24(32.9) \\
8(38.1) \\
13(33.3) \\
11(28.9) \\
12(20.0) \\
28(40.0) \\
16(23.9)\end{array}$} & \multirow{2}{*}{$\begin{array}{c}\mathbf{p} \\
0.176 \\
\end{array}$} \\
\hline Programlar & $\begin{array}{l}\text { ANS } \\
\text { RYT } \\
\text { ODY } \\
\text { IAY } \\
\text { RYT } \\
\text { TLT } \\
\text { TDS } \\
\text { NTT }\end{array}$ & & & \\
\hline Sinif & $\begin{array}{l}1 . \sin i f \\
2 . \sin i f\end{array}$ & $\begin{array}{l}169(68.1) \\
131(68.2)\end{array}$ & $\begin{array}{l}79(31.9) \\
61(31.8)\end{array}$ & 0.985 \\
\hline Cinsiyet & $\begin{array}{c}\text { KIz } \\
\text { Erkek }\end{array}$ & $\begin{array}{l}201(66.1) \\
99(72.8)\end{array}$ & $\begin{array}{l}103(33.9) \\
37(27.2)\end{array}$ & 0.175 \\
\hline Yaş & $\begin{array}{c}17-18 \\
19-21 \\
22 \text { ve üzeri }\end{array}$ & $\begin{array}{c}145(66.8) \\
135(72.2) \\
20(55.5)\end{array}$ & $\begin{array}{l}72(33.2) \\
52(27.8) \\
16(44.5)\end{array}$ & 0.077 \\
\hline Anne Eğitim & $\begin{array}{c}\text { Okur-Yazar değil } \\
\text { Okur-Yazar } \\
\text { İlkokul } \\
\text { Lise } \\
\text { Meslek Yüks.O. } \\
\text { Üniversite } \\
\text { Yüksek Lisans- } \\
\text { Doktora }\end{array}$ & $\begin{array}{c}21(77.8) \\
17(68.0) \\
181(70.2) \\
61(58.7) \\
3(50.0) \\
17(85.0) \\
-\end{array}$ & $\begin{array}{c}6(2.2) \\
8(32.0) \\
77(29.8) \\
43(41.3) \\
3(50.0) \\
3(15.0)\end{array}$ & 0.091 \\
\hline Babanın Eğitim & $\begin{array}{c}\text { Okur-Yazar değil } \\
\text { Okur-Yazar } \\
\text { İlkokul } \\
\text { Lise } \\
\text { Meslek Yük. O. } \\
\text { Üniversite } \\
\text { Yüksek Lisans- } \\
\text { Doktora } \\
\end{array}$ & $\begin{array}{c}16(84.2) \\
9(69.2) \\
147(69.0) \\
91(65.5) \\
8(61.5) \\
29(67.4) \\
-\end{array}$ & $\begin{array}{c}3(14.6) \\
4(30.8) \\
66(31.0) \\
48(34.5) \\
5(38.5) \\
14(32.6)\end{array}$ & 0.689 \\
\hline Aylık gelir & $\begin{array}{c}1-2000 \\
2001-5000 \\
5001 \text { ve üzeri }\end{array}$ & $\begin{array}{c}146(70.5) \\
131(65.8) \\
23(69.6)\end{array}$ & $\begin{array}{l}61(29.5) \\
68(34.2) \\
10(30.4)\end{array}$ & 0.586 \\
\hline $\begin{array}{c}6 \text { ayda bir diş } \\
\text { hekimine gitme }\end{array}$ & $\begin{array}{l}\text { Evet } \\
\text { Hayır }\end{array}$ & $\begin{array}{c}50(57.5) \\
250(70.8)\end{array}$ & $\begin{array}{c}37(42.5) \\
103(29.2)\end{array}$ & $0.017^{*}$ \\
\hline
\end{tabular}

ANS: Anestezi, TGT:Radyoloji ve tıbbi görüntüleme teknikleri, IAY: İlk ve acil yardım, ODY: Odyometri, TLT:Tıbbi laboratuar teknikleri, TDS: Tıbbi dokümantasyon ve sekreterlik, NTT:Nükleer tıp teknikleri, RYT: Radyoterapi, *p<0.005

\section{TARTIŞMA}

Son zamanlarda ADS'nin, genel sağlığa olan yakın ilgisi vurgulanarak sağlık çalışanlarının bu konuda eğitimlerini sağlamaya yönelik çalışmalar dikkati çekmektedir. ${ }^{2,6,9}$ Sağlık alanındaki birçok lisans 
eğitim müfredatında (tıp, eczacılık ve hemşirelik fakültelerinin öğrencilerine) ADS konusunda bilgi verilmektedir. ${ }^{2,12,17-19}$ Ancak bu çalışmalar genellikle doktor, hemşire ve ebelere yönelik olması nedeniyle tüm sağlık çalışanlarını içermemektedir. Oysaki sağlık bir bütündür ve bu alanda çalışan tüm bireylerin eğitimleri sırasında ADS konusunda doğru bilgilere sahip olmaları önemlidir. Ülkemizde bulunan birçok SHMYO müfredatında ADS konusuna yer verilmediği bilinmektedir. SHMYO eğitimi ADS konularını da içerecek şekilde yapılandırılması ve öğrencilerin bu konudaki yeterliliklerinin artırılması gerekmektedir.

Yaşar ve ark. ${ }^{20}$ tıp fakültesi öğrencilerinin ADS konusunda bilgilerini \%35 ebeveynlerinden, \%19'u kişisel merakla, \%18'i diş hekiminden, \%15'i yayın kuruluşlarından, \%13'ü ise okulda aldıkları eğitimle edindiklerini belirtmişlerdir. Çalışmamızda da benzer şekilde öğrencilerin büyük bir kısmı diş fırçalamayı ebeveynlerinden (\%39.3) öğrendiklerini söylemişlerdir.

Düzenli diş fırçalamanın, diş çürüğünü azalttığı bilinmektedir. Dişlerini günde iki kez düzenli fırçalayanların ve bu alışkanlığı erken yaşta edinenlerin daha az diş çürüğü olduğu çalışmalarda gösterilmiştir. 17,21,22 Ayrıca bu alışkanlığın edinilmesinde, ailelerin sosyoekonomik ve eğitim düzeylerinin etkili olduğu öne sürülmektedir. ${ }^{9,17,21}$ Çalışmamızda ADS problemi yaşayan öğrenci oranı \%77.7 olarak bulunmuştur. ADS problemleri içinde \%79.8 gibi büyük grubu diş çürüğü problemi oluşturmaktadır. Ülkemizde tüm yaş gruplarının ortalaması alındığında her 100 kişiden 92'sinin çürük nedeniyle tedaviye gereksinimi olduğu bilinmektedir. ${ }^{23}$

Dişler günde kaç kez fırçalanmalıdır, sorusuna öğrencilerin \%40.0'i doğru yanıt vermiştir. ADS konusunda yapılan birçok çalışmada bu oran \%50-78 arasında bulunmuştur. 2,17,20 Bizim bulgumuz diğer araştırıcıların bulgularından daha düşüktür. Bunu çalışmaların tıp fakültesi öğrencilerinde yapılmış olmasına bağlamaktayız.

DEU SHMYO 1. ve 2. sınıf öğrencilerinin ADS bilgi düzeyini ölçen on sekiz sorudan oluşan soru formunda 10 ve üzeri soruya doğru cevap veren öğrenci oranı \%31.8 (ortalama $8.24 \pm 2.44$ soru) olarak bulunmuştur. Tıp fakültesi öğrencileri üzerinde yapılmış çalışmalarda ADS sorularına doğru cevap verme oranı \%40-52 arasında bulunmuştur. ${ }^{24,25}$

Çalışmamızda yaş $(p=0.077)$, cinsiyet $(p=$ $0.175)$, ve programlar $(p=0.176)$ arasında ADS bilgi düzeyinde istatistiksel olarak fark saptanamamıştır. Sharda ve ark. ${ }^{6}$ tıp dişı, para-medical ve tıp öğrencilerin ADS bilgi düzeylerini inceleyen çalışmalarında tıp öğrencilerinin bilgi düzeyinin diğer iki gruptan daha iyi olduğunu belirtmişlerdir. Ayrıca tüm gruplar içinde ADS bilgi düzeyinde kIz öğrencilerin erkeklerden daha bilgili olduklarını saptamışlardır. Bizim bulgularımızda cinsiyetle ADS bilgi düzeyi arasında fark görülmemiştir.

Bilgi düzeyi sorularına verilen yanıtlara bakıldığında; tütün ve tütün ürünleri diş ve dişetine zarar verir mi sorusu öğrencilerin \%92'si tarafından doğru yanıt verilen soru olmuştur. Bu oldukça yüksek bir orandır ve öğrencilerin tütünün ADS zararlı etkileri olduğunu bilmesi olumludur. Ancak öğrenciler, tütünün ADS zararlı etkisini bilmelerine rağmen \%28.9'ü tütün ve tütün ürünü kullandıklarını belirtmiş̧lerdir. Türkiye'de üniversite öğrencileri arasında sigara içme sıklığı \%20-48'dir. ${ }^{26,27}$ Ülkemizde SHMYO öğrencilerinin tütün ve tütün ürünü kullanımına yönelik yapılan çalışmalarda bu oran \%37,5-55,0 bulunmuştur. ${ }^{28,29}$ Bizim bulgumuz diğer SHMYO öğrencilerinin tütün kullanma oranından daha düşüktür. Çalışmalar arasındaki bu farklılı̆ın nedenini 2010 yılı sonrasında tütün ve tütün ürünleri kullanımına yönelik halk sağlığı alanında yapılmış çalışmaların etkisine bağlamaktayız.

Çalışmamızda yılda iki kez düzenli diş hekimi ziyaretinde bulunan öğrencilerin ADS bilgi düzeyinin daha yüksek olduğu ve farkın istatistiksel olarak anlamlı olduğu görülmüştür. Adeghe ve ark. ${ }^{25}$ bulgularımıza benzer şekilde düzenli diş hekimi kontrolüne giden tıp fakültesi öğrencilerinin, gitmeyenlere göre ADS konusunda bilgi düzeyinin daha iyi olduğunu belirtmişlerdir.

SHMYO öğrencilerin en fazla doğru cevap verdiği diğer sorular, diş macunu miktarının (\%84.1), diş temizliğinde kullanılan ürünlerin neler olduğu (\%78.0), dişlerin çürümesine nelerin neden olduğu (\%75.2), kaç adet daimi dişimiz bulunduğu (\%68.4) sorularıdır. Koşan ve ark. ${ }^{30}$ tıp fakültesi öğrencilerinin "kaç adet daimi dişimiz vardır" sorusuna \%66.9, "dişlerin çürümesine neler neden olur" sorusuna da \%60.2 oranında doğru cevap verdiklerini belirtmişlerdir. Bu bulgular bizim çalışmamızın bulgularına oldukça yakındır.

Öğrencilerin en az bildiği sorular içinde "ilk daimi dişler kaç yaşında çıkar" (\%34.1), "kaç adet süt dişimiz vardır" (\%20.2), "çocuklar dişlerini ne zaman fırçalamaya başlamalıdır" (\%19.1) soruları olmuştur. Koşan ve ark. ${ }^{30}$ tıp fakültesi öğrencilerinde ilk daimi diş çıkma yaşını bilme oranını \%37.6 bulurken, kaç "adet süt diş vardır" sorusuna verilen doğru cevap oranını \%36.8 olarak bulmuşlardır. Ayık ve ark. ${ }^{31}$ hemşire ve ebelerin ADS bilgi düzeyi araştıran 
çalışmalarında en az doğru cevaplanan sorunun "çocuklar dişlerini ne zaman fırçalamaya başlamalıdır" (\%11.0) sorusu olduğunu belirtmişlerdir. Her iki araştırıcının bulguları bizim bulgularımıza yakındır. ${ }^{30,31}$ ADS konusunda bilgi düzeyine yönelik daha çok tıp ve hemşirelik fakültesi öğrencileri üzerinde çalışmalar yapılmış olması nedeniyle verilerimizi bu çalışmalarla karşılaştırabilmekteyiz. Ancak ADS konusunda tıp ve hemşirelik fakültesi öğrencilerinin bilgi düzeyi SYMYO öğrencilerinin bilgi düzeyine oldukça yakın olduğu görülmektedir. Bu veriler bize sağılk alanında eğitim alan tıp, hemşirelik eczacılık ve SHMYO öğrencilerinin ADS bilgi düzeyleri arasında çok büyük farklılı̆ın olmadığını göstermektedir.

Sonuç olarak çalışmaya katılan DEU SHMYO öğrencilerinin ADS konusunda bilgi düzeylerinin orta ve düşük düzeyde olduğu saptanmıştır. SHMYO mezuniyet öncesi eğitimleri sırasında ADS konusunda eğitim verilmesinin önemli olduğu ve bunun toplum sağlığı açısından yararlı olacağı kanısına varılmıştır.

NOT: Çalışmada herhangi bir yazar, kurum ya da kuruluş ile çıkar çatışması içerisinde bulunmamaktadır. Makale daha önce hiçbir yerde yayınlanmamış ve yayınlanmak üzere işlem görmemektedir

\section{KAYNAKLAR}

1. Tabak RS, Akköse K, Ergenlerin sağlık denetim odağı algılama düzeyleri ve sağlık davranışlarına etkileri. TAF Preventive Medicine Bulletin 2006: 5:118-26.

2. Kılınç G, Günay T. Dokuz Eylül Üniversitesi Tıp Fakültesi son sınıf öğrencilerinin ağız diş sağığı konusunda bilgi düzeyleri. DEÜ Tıp Fak Derg 2010; 24:131-7.

3. Jin L, Lamster IB, Greenspan JS, Pitts NB, Scully C, Warnakulasuriya S. Global burden of oral diseases: Emerging concepts, management and interplay with systemic health. Oral Dis 2016; 22: 609-19.

4. Linden GJ, Lyons A, Scannapieco FA. Periodontal systemic associations: Review of the evidence. J Clin Periodontol 2013; 40: 8-19.

5. Park JB, Han K, Park YG, Ko Y. Association between socioeconomic status and oral health behaviors: The 2008-2010 Korea national health and nutrition examination survey. Exp Ther Med 2016; 12: 2657-64.
6. Sharda AJ, Shetty S. A comparative study of oral health knowledge, attitude and behaviour of non-medical, para-medical and medical students in Udaipur city, Rajasthan, India. Int J Dent Hyg 2010;8:101-9.

7. Marmot M, Bell R. Social determinants and dental health. Adv Dent Res 2011;23:201-12.

8. Sharda A, Sharda J. Factors influencing choice of oral hygiene products used among the population of Udaipur, India. Int J Dent Clin 2010;2:7-12.

9. Gürsoy H, Dölekoğlu S, Özçakır Tomruk C, Özkurt Kayahan Z. Yeditepe üniversitesi dişhekimliği fakültesi öğrencilerinde ağız diş sağlığı tutum ve davranışlarının değerlendirilmesi. Atatürk Üniv Diş Hek Fak Derg 2016;26:1-7.

10. Okutan Y, Dönmez MB, Yücel MT.Sosyoekonomik şartların diş hekimliği öğrencilerinin ağız sağlığına olan etkisi: Anket çalışması. Selcuk Dent J 2017;4: 59-67.

11. Dilip CL. Health status, treatment requirements, knowledge and attitude towards oral health of police recruits in Karnataka. J Ind Assoc Pub Health Dent 2005;5:20-34.

12. Türkoğlu Ö, Dülgergil ÇT. Hemşirelik Eğitiminde Yer Alan Toplum-Ağız-Diş-Sağlığı Dersinin, Öğrencilerin Ağız-Diş Sağlığı Farkındalığına Etkisinin Değerlendirilmesi. Türkiye Klinik J Dental Sci 2015;21:221-8.

13. Develioğlu H, Gedik R, Tufan N, Yalçın D. Bireylerin oral hijyen araçları ve bilgilerinin araştırılması. CÜ Diş Hek Fak Derg 2001;4:15-9.

14. Gökalp S, Doğan BG. Erişkin ve yaşlılarda ağız diş sağlığı profili Türkiye 2004. Hacettepe Diş Hek Derg 2007;31:11-8.

15. Gökalp S, Doğan BG. Beş, on iki ve on beş yaş çocukların ağız diş sağlığı profili Türkiye 2004. Hacettepe Diş Hek Derg 2007; 31:3-10.

16. Şanlıer N, Özgen L. Öğrencilere farklı yöntemlerle verilen eğitimin ağız diş sağlığı ve beslenme bilgisi üzerine etkisi. Türk Eğitim Bilim Derg 2005;3:35165.

17. Erdoğan A, Bozkurt Aİ, Ergin A, Topaloğlu $S$, Aydın A, Arslan A, Avcı A, Kurtcephe B, Er F, Çevik İ, Karagöz K, Kahyaoğlu M. Pamukkale Üniversitesi Tıp Fakültesi öğrencilerinde ağız-diş sağlığının değerlendirilmesi Pam Tıp Derg 2015;8:1-9.

18. Özveren H, Gülnar E, Özden D. Hemşirelik öğrencilerinin ağız diş sağlığı algılarının belirlenmesi. KÜ Tıp Fak Derg 2017;19:158-66. 
KILINÇ, YURT, MANİSALIGİL, KIZILDAG

19. Bashiru BO, Omotola OE. Oral health knowledge, attitude and behavior of medical, pharmacy and nursing students at the University of Port Harcourt. Nig J Oral Res Rev 2016; 8:66-71.

20. Yaşar F, Çalışkan D, Yıldız A. Ankara University Faculty of Medicine, oral health of students in grade 5 and daily oral care habits. Ankara Üni Tıp Fak Mec 2007;60:13-9.

21. Gibson S, Williams S. Dental caries in pre-school children: association with social class, toothbrushing habit and consumption of sugars and sugar-containing foods. Further analysis of data from the National Diet and Nutrition Survey of children aged 1.5-4.5 years. Caries Res 1999;33:101-13.

22. Güngör K, Tüter G, Bal B. Eğitim düzeyi ile ağız sağlığı arasındaki ilişkinin değerlendirilmesi. GÜ Diş Hek Fak Derg 1999;16:15-20.

23. Ulu O, Doğruer I, Usta UA, Dörter C. Oral hygiene behaviour change in dentistry students during dental education. J Istanbul Uni Fac Dent 2012;46:29-42.

24. Rabiei S, Mohebbi SZ, Patja K, Virtanen JI. Physicians knowledge of and adherence to improving oral health. BMC Public Health 2012;12:855.

25. Adeghe HA, Ehigiator O, Azodo CC, Ehizele AO. Nigerian clinical level medical students' knowledge of dental specialty. Ann Med Health Sci Res 2012; 2: 157-60.

26. Kılınç G, Bolgül BS, Aksoy G, Günay T. The Prevelance of Tobacco Use and the Factors Influencing in Students Studying at Two Dentistry Faculties in Turkey. Turk Thorac J 2016; 17: 4752.

27. Keskinler D, Güraksın A, İnandı $T$, et al. Atatürk Üniversitesi öğrencilerinde sigara içme prevalansı ve etkili faktörler. AÜTD 1999;31:112-6.

28. Kılıç N, Ek HN. Adnan Menderes Üniversitesi sağlık yüksekokulu ve sağlık hizmetleri meslek yüksekokulu öğrencilerinin sigaraya yönelik, bilgi, tutum ve davranışları. Sağlık Bil Derg 2006;15:8590.
29. Hassoy H, Ergin I, Davas A, Durusoy R, Karababa $O A$. Determining the factors effecting the cigarette, narghile and hand- rolled tobacco smoking among medical technology vocational training school students and evaluation of their opinions about starting and continuing with their habits of smoking. Respiratory J 2011;13: 91-9.

30. Koşan Z, Akgül N, Bedir B, Çalıkoğlu EO, Yılmaz S, Derelioğlu SŞ. Tıp ve diş hekimliği fakültelerinde ağız diş sağlığı eğitimi yeterli mi? Öğrencilerin bilgi düzeylerinin karşılaştırması. Turk J Public Health 2017;15:201-11.

31. Ayık Y, Özçelik SK, Akyüz S, Bahçecik AN. Hemşirelik ve ebelik öğrencilerinin ağız diş sağlığı konusunda bilgi düzeyleri. Clin Exp Health Sci 2017; 7: 159-65.

\section{Yazışma Adresi}

Dr. Gülser KILINÇ

Dokuz Eylül Üniversitesi

Tıp Fakültesi, Çocuk Diş Kliniği,

İzmir, Türkiye

Tel: 00902324122181

e-mail: gulser.kilinc@deu.edu.tr 